\title{
TI.59.1
}

\section{IDtrust 2010 - 9th Symposium on Identity and Trust on the Internet}

- PDF: 9thAnnuallDTrustWorkshop.pdf

- Text: 9thAnnualIDTrustWorkshop.txt

\section{More Information}

\begin{tabular}{|c|c|}
\hline Repository ID & TI.59.1 \\
\hline Persistent URL & http://doi.org/10.26869/TI.59.1 \\
\hline Title & IDtrust 2010 - 9th Symposium on Identity and Trust on the Internet \\
\hline Authors & Ken Klingenstein, et al \\
\hline Sponsor & NIH, NIST, Internet2 \\
\hline \multicolumn{2}{|l|}{ Review } \\
\hline Status & Legacy \\
\hline Publish Date & April 13-15, 2010 \\
\hline DOI & 10.26869/TI.59.1 \\
\hline \multicolumn{2}{|l|}{ Signature } \\
\hline Deprecated & No \\
\hline \multicolumn{2}{|l|}{ Future Review } \\
\hline \multicolumn{2}{|l|}{ Supersedes } \\
\hline Format & PDF, Text \\
\hline \multicolumn{2}{|l|}{ Related Docs } \\
\hline \multicolumn{2}{|l|}{ Development Location } \\
\hline \multicolumn{2}{|l|}{ IP Framework } \\
\hline Subject Tags & middlewarerescue \\
\hline Notes & \\
\hline
\end{tabular}

